\title{
PENGARUH AROMATERAPI KENANGA (CANANGA ODORATA) TERHADAP PENURUNAN TEKANAN DARAH PADA PASIEN HIPERTENSI
}

\author{
Kristina L Silalahi', Fajar Amanah Ariga ${ }^{2}$, Patimah Sari Siregar ${ }^{3}$ \\ Fakultas Keperawatan dan Kebidanan Universitas Prima Indonesia, Medan \\ E-mail: kristinasilalahi@unprimdn.ac.id; fajaramanahariga@unprimdn.ac.id; \\ patimahsarisiregar@unprimdn.ac.id
}

\begin{abstract}
Hypertension is one of the biggest problems that cause death because many are undiagnosed and hypertensive sufferers often experience asymptomatic events causing difficulty to know the causes of hypertension. Treatment of hypertension can perform by pharmacology and non-pharmacology. Non-pharmacological treatment may be in the form of aromatherapy. This study aimed to determine the effect of aqueous aromatherapy on the decrease of blood pressure in hypertensive patients at Royal Prima Hospital Medan in 2017. The study design was quasi-experiment with one group pretest-postest design provided with aromatherapy for 10 minutes. The population consisted of 28 people. The 10 people as sampling were drawn by a purposive sampling technique. Data collection was performed by interview and observation. The bivariate analysis used was paired sample t-test with a significance level of 0.05 (5\%). The results showed that the level of systolic and diastolic blood pressure before aromatherapy aqueous treatment was $156.60 \mathrm{mmHg}$ and $92.40 \mathrm{mmHg}$. Systolic and diastolic blood pressure after aqueous aromatherapy administration was $142.60 \mathrm{mmHg}$ and $81.80 \mathrm{mmHg}$. Based on the results of statistical tests it was found that there was a difference in blood pressure between before and after aromatherapy, \{systolic, $p$-value $=0.000(p<0.05)$ and diastolic, $p$ value $=0.000(p<0.05)\}$. The results of this study concluded that there is an effect of giving aqueous aromatherapy (Kananga odorata) on the decrease of blood pressure in hypertension patients at Royal Prima Hospital Medan in 2017. It is suggested that aqueous aromatherapy can be applied as an alternative therapy to lower blood pressure.
\end{abstract}

Keywords: aromatherapy, ylang ylang, blood pressure, hypertension

\section{PENDAHULUAN}

Hipertensi lebih dikenal sebagai terjadinya peningkatan tekanan darah. Penyakit hipertensi disebut sebagai "silent killer" karena fakta bahwa kebanyakan pasien dengan hipertensi tidak menunjukkan gejala apapun atau memiliki gejala yang mungkin tidak jelas atau tidak spesifik (Kumanan, Guruparan, \& Sreeharan, 2018). Konsekuensi kesehatan yang merugikan dari hipertensi diperparah karena banyak orang yang terkena juga memiliki faktor risiko kesehatan lain yang meningkatkan kemungkinan serangan jantung, stroke, dan gagal ginjal (World Health Organization, 2013).

Peningkatan tekanan darah di seluruh dunia diperkirakan menyebabkan 7,5 juta kematian, sekitar $12,8 \%$ dari total seluruh kematian. Hal ini menyumbang 57 juta tahun hidup yang disesuaikan dengan kecacatan (DALYS) atau 3,7\% 
dari total DALYS (World Health Organization, 2016).

Berdasarkan Riskesdas tahun 2018 prevalensi hipertensi berdasarkan hasil pengukuran pada penduduk usia 18 tahun sebesar $34,1 \%$, tertinggi di Kalimantan Selatan (44.1\%), sedangkan terendah di Papua sebesar $(22,2 \%)$. Prevalensi hipertensi provinsi Sumatera Utara sebesar 29,2\%. Hipertensi terjadi pada kelompok umur 31-44 tahun (31,6\%), umur 45-54 tahun (45,3\%), umur 55-64 tahun

(Kementerian Kesehatan RI, 2019).

Penting untuk disadari bahwa mayoritas (lebih dari 95\%) kasus hipertensi yang terlihat dalam praktik klinis disebabkan oleh hipertensi Essential atau Primer (yaitu tidak ada penyebab yang pasti) di mana hipertensi dalam banyak kasus berkembang secara bertahap seiring waktu dengan bertambahnya usia (Kumanan et al., 2018).

Kejadian penyakit hipertensi yang meningkat setiap tahun perlu mendapatkan perhatian dan segera diatasi. Pengobatan hipertensi terdiri dari terapi farmakologis dan non farmakologis. Terapi farmakologis yaitu obat anti hipertensi sedangkan terapi non farmakologis terdiri dari menghentikan merokok, menurunkan berat badan berlebih, latihan fisik, menurunkan asupan garam, meningkatkan konsumsi buah dan sayur serta menurunkan asupan lemak (Potter \& Perry, 2015). Pemberian terapi non farmakologis relatif praktis dan efisien yaitu dengan cara pemberian aromaterapi.

Aromaterapi merupakan salah satu terapi pelengkap yang menggunakan minyak atsiri sebagai agen terapeutik utama untuk mengobati beberapa penyakit. Minyak esensial atau minyak atsiri diekstraksi dari bunga, kulit kayu, batang, daun, akar, buah-buahan dan bagian tanaman lainnya dengan berbagai metode. Penghirupan, aplikasi lokal dan mandi adalah metode utama yang digunakan dalam aromaterapi yang memanfaatkan minyak ini untuk menembus permukaan kulit manusia dengan aura yang jelas (Ali et al., 2015).

Minyak esensial kenanga (Cananga Odorata) merupakan salah satu jenis aromaterapi yang mempunyai beberapa kandungan senyawa alami seperti asam bensoat, geraniol, farnesol, geraniol, eugenol, linalool, sadrol (Sharma, 2008). Sebuah studi percontohan yang melibatkan 34 profesional dari sebuah kelompok perawat dilakukan di Portugal untuk memverifikasi penggunaan minyak esensial ylang ylang dalam meredakan kecemasan dan meningkatkan harga diri seiring dengan perubahan tekanan darah dan suhu. Hasil penelitian Gnatta, Piason, Lopes, 
Rogenski, dan Silva, (2014) menunjukkan bukti yang jelas bahwa penggunaan tanaman ini menyebabkan perubahan harga diri yang signifikan. Menurut Zulmi (2016), aromaterapi kenanga bersifat menenangkan, lansia yang diberikan aromaterapi kenanga memiliki peningkatan kuaitas tidur malam yang lebih lama dari pada sebelum pemberian aromaterapi.

Studi pendahuluan yang telah dilakukan peneliti pada di RSU Royal Prima Medan pada bulan Januari sampai dengan April 2017 terdapat 110 pasien penderita hipertensi yang rawat inap. Berdasarkan hasil observasi dan wawancara kepada 10 pasien, mendapatkan data sebanyak 4 orang pasien tidak mengetahui tentang penyakit yang dideritanya, 3 pasien sebagai hipertensi terkontrol dan 3 pasien hipertensi lainnya minum obat tetapi tidak rutin, dan dari 10 pasien tersebut tidak ada yang memakai obat herbal sebagai pengobatan hipertensi.

Berdasarkan fenomena tersebut diatas peneliti tertarik untuk melakukan penelitian tentang pengaruh pemberian aromaterapi kenanga (Cananga Odorata) terhadap penurunan tekanan darah pada pasien hipertensi.

\section{METODE}

Jenis penelitian yang digunakan dalam penelitian ini adalah Quasi- experiment Design dengan menggunakan rancangan One group pretest and posttest design yaitu rancangan yang menggunakan satu kelompok sampel yang sama dan dilakukan pengukuran sebanyak dua kali, yaitu dilakukan sebelum perlakuan (pretest) dan dilakukan sesudah diberikan perlakuan (posttest).

Penelitian ini dilakukan di Rumah Sakit Umum Royal Prima di lantai 9 dan lantai 10. Penelitian dilakukan pada 10 Juli - 5 Agustus 2017.

Populasi penelitian adalah seluruh pasien yang mengalami hipertensi sebanyak 25 pasien. Pengambilan sampel menggunakan tehnik purposive sampling, dengan kriteria pasien disarankan tidak sedang meminum obat hipertensi selama terapi ini diberikan. Jumlah sampel dengan hipertensi sebanyak 10 pasien.

Instrumen penelitian yang digunakan berupa lembar observasi yang berisi tentang pengamatan tekanan darah pretest dan tekanan darah posttest hari pertama dan hari ke lima. Alat dan bahannya sebagai berikut: (1) Alat yang digunakan spigmomanometer dengan merek One Med, stetoskop merek GEA Medical, tisu, arloji, pipet tetes, dan (2) Bahan yang digunakan adalah aromaterapi kenanga yang diproduksi oleh Nusaroma dan di proses menggunakan alat seperti Gas 
Chromathogtaphy, Mass Spectrometry, Refraktormeter Hydrometer.

Format informed consent yang diberikan langsung oleh peneliti menjelaskan tentang aromaterapi ini dilakukan selama tujuh hari dengan meneteskan minyak sebanyak 2-3 tetes ke sapu tangan pasien dan menghirupnya secara berlahan-lahan sambil menikmati rileksasi. Aromaterapi ini diberikan setiap hari di pagi hari.

Peneliti melakukan pretest untuk memperoleh data tentang nilai tekanan darah pada setiap responden. Setelah dilakukannya aromaterapi selama tujuh hari berturut-turut maka peneliti melakukan posttest kembali untuk mengetahui nilai perubahan yang terjadi akibat aromaterapi yang telah diberikan terhadap seluruh sampel penelitian.

Analisis univariat mendeskripsikan karakteristik variabel penelitian. Data diolah dalam bentuk distribusi frekuensi.

Analisa bivariat dilakukan dengan uji Paired Sample t-test yaitu uji untuk satu kelompok berpasangan untuk mengetahui pengaruh pemberian aromaterapi kenanga terhadap penurunan tekanan darah.

\section{HASIL DAN PEMBAHASAN}

Hasil

\section{Analisa Univariat}

Berdasarkan hasil penelitian pengaruh pemberian aromaterapi kenanga (Cananga Odorata) terhadap penurunan tekanan darah pada pasien hipertensi yang dilakukan selama 14 hari dan diberikan selama 10 menit dengan frekuensi 5 kali pemberian.

Tabel 1.Distribusi Frekuensi Karakteristik Responden

\begin{tabular}{|c|c|c|c|}
\hline No & Karakteristik & $f$ & $\begin{array}{c}\text { Persentase } \\
(\%)\end{array}$ \\
\hline \multirow{4}{*}{1.} & Jenis Kelamin & & \\
\hline & Laki-Laki & 4 & 40 \\
\hline & Perempuan & 6 & 60 \\
\hline & Total & 10 & 100 \\
\hline & Umur & & \\
\hline & $<55$ tahun & 4 & 40 \\
\hline & 55-59 tahun & 2 & 20 \\
\hline & $>59$ tahun & 4 & 40 \\
\hline & Total & 10 & 100 \\
\hline \multirow[t]{7}{*}{3.} & Pendidikan & & \\
\hline & SD & 1 & 10 \\
\hline & SLTP & 4 & 40 \\
\hline & SLTA & 3 & 30 \\
\hline & Perguruan & 2 & 20 \\
\hline & Tinggi & & \\
\hline & Total & 10 & 100 \\
\hline
\end{tabular}

Responden penelitian ini lebih banyak berjenis kelamin perempuan, yaitu sebanyak 6 orang (60\%) selebihnya, yaitu laki-laki berjumlah 4 orang $(40 \%)$. Berdasarkan umur lebih banyak pada rentang usia di bawah 55 tahun, yaitu sebanyak 4 orang (40\%), usia diatas 59 tahun sebanyak 4 orang (40\%) dan di rentang 55-59 tahun sebanyak 2 orang (20\%). Berdasarkan pendidikan lebih banyak tamatan SLTP, yaitu berjumlah 4 orang (40\%), tamatan SLTA berjumlah 3 orang (30\%), tamatan Perguruan Tinggi berjumlah 2 
orang $(20 \%)$, dan 1 orang (10\%) tamatan SD.

Tabel 2. Distribusi Frekuensi Rerata Tekanan Darah Sebelum dan Sesudah Pemberian Aromaterapi Kenanga Selama 5 Hari

\begin{tabular}{|c|c|c|c|c|c|}
\hline \multicolumn{3}{|c|}{$\begin{array}{l}\text { Tekanan Darah } \\
\text { Sebelum }\end{array}$} & \multicolumn{3}{|c|}{$\begin{array}{c}\text { Tekanan Darah } \\
\text { Sesudah }\end{array}$} \\
\hline Sistol & Diastol & $f$ & Sistol & Diastol & $f$ \\
\hline 148 & 84 & 1 & 138 & 76 & 1 \\
\hline 160 & 100 & 1 & 150 & 90 & 1 \\
\hline 156 & 90 & 1 & 146 & 80 & 1 \\
\hline 150 & 90 & 1 & 140 & 82 & 1 \\
\hline 164 & 102 & 1 & 146 & 84 & 1 \\
\hline 150 & 92 & 1 & 130 & 82 & 1 \\
\hline 164 & 98 & 1 & 150 & 86 & 1 \\
\hline 156 & 90 & 1 & 142 & 80 & 1 \\
\hline 158 & 90 & 1 & 138 & 80 & 1 \\
\hline 160 & 88 & 1 & 146 & 78 & 1 \\
\hline \multicolumn{2}{|c|}{ Total } & & \multicolumn{2}{|c|}{ Total } & 10 \\
\hline
\end{tabular}

Berdasarkan Tabel 2 tekanan darah sebelum pemberian aromaterapi kenanga di Rumah Sakit yang paling banyak adalah tekanan darah sistolik $150 \mathrm{mmHg}$ (20\%), $156 \mathrm{mmHg}$ (20\%), $160 \mathrm{mmHg}$ (20\%), dan $164 \mathrm{mmHg}$ (20\%). Tekanan darah diastolik paling banyak $90 \mathrm{mmHg}$ (40\%). Rata-rata tekanan darah sistolik adalah 156.60 $\mathrm{mmHg}$ dan rata-rata tekanan darah diastolik adalah $92.40 \mathrm{mmHg}$.

Hasil pengukuran tekanan darah sesudah pemberian aromaterapi kenanga di Rumah Sakit, dengan nilai terbanyak sistolik adalah $146 \mathrm{mmHg}$ (30\%). Nilai terbanyak diastolik adalah $80 \mathrm{mmHg}$ $(30 \%)$. Rerata nilai dari sistolik adalah
$142.60 \mathrm{mmHg}$ dan rata-rata nilai diastolik adalah $81.80 \mathrm{mmHg}$.

\section{Analisa Bivariat}

Pengaruh tekanan darah sebelum dan sesudah pemberian aromaterapi kenanga terhadap penurunan tekanan darah pada pasien hipertensi dapat dilihat di Tabel 3 yaitu:

\begin{tabular}{|c|c|c|c|c|c|}
\hline & $\begin{array}{l}\text { 3. Peng } \\
\text { Aron } \\
\text { terha } \\
\text { Teka } \\
\text { Hipe }\end{array}$ & $\begin{array}{l}\text { ruh } \\
\text { iterapi } \\
\text { ap } \\
\text { an Dara } \\
\text { ensi }\end{array}$ & $\begin{array}{r}\text { Per } \\
\text { K } \\
\text { Pen } \\
\text { h pada }\end{array}$ & $\begin{array}{l}\text { nberian } \\
\text { enanga } \\
\text { urunan } \\
\text { Pasien }\end{array}$ & \\
\hline No & $\begin{array}{c}\text { Tekanan } \\
\text { Darah }\end{array}$ & Mean & SD & $T$-test & $\begin{array}{c}p- \\
\text { value }\end{array}$ \\
\hline & $\begin{array}{l}\text { Sistolik } \\
\text { sebelum }\end{array}$ & 156.60 & 5.739 & & \\
\hline 1 . & $\begin{array}{l}\text { Sistolik } \\
\text { sesudah }\end{array}$ & 142.60 & 6.257 & 10.773 & 0.00 \\
\hline & $\begin{array}{l}\text { Diastolik } \\
\text { sebelum }\end{array}$ & 92.40 & 5.719 & & \\
\hline & $\begin{array}{l}\text { Diastolik } \\
\text { sesudah }\end{array}$ & 81.80 & 4.050 & & 0.000 \\
\hline
\end{tabular}

Berdasarkan Tabel 3 data yang telah diperoleh berdistribusi normal, menggunakan Uji-Paired Sample T Test dengan tingkat kepercayaan 95\%. Hasil nilai $p$-value $=0.000<0.05$ yang berarti hubungan (korelasi) antara tekanan darah sistolik sebelum dan sesudah sangat erat.

\section{Pembahasan}

Hasil penelitian ini mendapatkan penderita lebih banyak pada perempuan dan yang berusia di atas 59 tahun. Seiring dengan penambahan usia, maka setiap orang akan rentang mengalami penyakit, disebabkan karena penurunan kinerja organ tubuh dan menurunnya 
sistem imun yang dapat mempengaruhi kesehatan, sehingga semakin bertambahnya usia seseorang memiliki resiko tinggi terjadinya penyakit terutama penyakit hipertensi.

Hipertensi didefinisikan sebagai tekanan darah sistolik sama dengan atau di atas $140 \mathrm{~mm} \mathrm{Hg}$ dan / atau tekanan darah diastolik sama dengan atau di atas $90 \mathrm{~mm} \mathrm{Hg}$ (World Health Organization, 2013). Faktor-faktor yang berhubungan dengan kejadian hipertensi yaitu usia, jenis kelamin, pekerjaan, pendapatan, pendidikan, riwayat keluarga, akses ke pelayanan kesehatan, pola aktivitas fisik, dan pengetahuan, pola konsumsi makanan asin dan konsumsi makanan berlemak (Ningsih \& Indriani, 2017). Hipertensi biasanya disertai dengan faktor risiko yang dapat dimodifikasi dan komorbiditas seperti obesitas, merokok, aktivitas fisik, diabetes dan dislipidemia, yang harus diidentifikasi dan diobati untuk membantu mengontrol tekanan darah dan mengurangi komplikasi kardiovaskular (Kumanan et al., 2018).

Berdasarkan observasi, penderita hipertensi sebagian besar berpendidikan SLTP. Tingkat pendidikan yang rendah dapat mempengaruhi sikap dan perilaku dalam mencegah dan mengobati penyakit hipertensi, sehingga penderita cenderung tidak mengetahui pengobatan dan cara mengatasi penyakit hipertensi.
Proporsi hipertensi menurut tingkat pendidikan yang menunjukkan kecenderungan penurunan seiring dengan meningkatnya tingkat pendidikan. Riskesdas 2013 dan 2018 menunjukkan proporsi hipertensi pada kelompok penduduk tidak/belum pernah sekolah sebesar $42 \%$ dan $51,6 \%$ yang menunjukkan penurunan hingga $22,1 \%$ dan $28,3 \%$ pada kelompok yang tamat D1/D2/D3/PT (Kemenkes RI, 2019).

Salah satu upaya dalam penatalaksanaan hipertensi dengan terapi nonfarmakologis, yaitu dengan pemberian aromaterapi kenanga. Hal ini disebabkan oleh zat flavonoid yang dapat meningkatkan gelombang alfa di dalam otak dan gelombang inilah yang membantu untuk rileksasi, dan dapat menurunkan aktifitas vasokonstriksi pembuluh darah, aliran darah menjadi lancar sehingga menurunkan tekanan darah (Sharma, 2008).

Hasil penelitian takanan darah sebelum pemberian aromaterapi kenanga dengan rata-rata sistolik 156.60 mmHg dan diastolik 92.40 dengan Standard Deviasi sistolik menunjukkan bahwa 5.739 dan diastolik 5.719. Hal ini menunjukkan sebagian responden termasuk dalam kategori hipertensi ringan. Menurut data Kemenkes RI, (2019), berdasarkan variabel umur dan jenis kelamin, kelompok yang banyak berkontribusi terhadap ketidakpatuhan 
pengukuran tekanan darah adalah kelompok umur 18-24 tahun dengan proporsi sebesar 55,3\% dan laki-laki sebesar $50,5 \%$.

Pengukuran tekanan darah dilakukan sebelum pemberian aromaterapi selama 10 menit. Tekanan darah responden diukur kembali setelah pemberian aromaterapi. Pengukuran tekanan darah menggunakan Spygmomanometer dan stetoskop yang hasilnya dicatat di lembar observasi. Setelah dilakukan pemberian aromaterapi dengan minyak kenanga diketahui bahwa rata-rata sistolik $142.60 \mathrm{mmHg}$ dan diastolik 81.80 mmHg. Hasil penelitian menunjukkan terjadi penurunan tekanan darah sebelum dan sesudah pemberian aromaterapi kenanga, yaitu rerata tekanan darah sistolik sebelum pemberian aromaterapi sebesar 156.60 $\mathrm{mmHg}$ dan setelah pemberian aromaterapi sebesar $142.60 \mathrm{mmHg}$. Rerata tekanan darah diastolik sebelum pemberian aromaterapi sebesar 92.40 $\mathrm{mmHg}$ dan setelah pemberian aromaterapi sebesar $81.80 \mathrm{mmHg}$.

Saat aromaterapi kenanga masuk melalui hidung, aroma akan diterima oleh cilia dalam hidung yang kemudian akan di kirim ke sistem limbic dalam bentuk impuls listrik. Impuls ini memberikan efek, dimana sistem ini yang menjadi pusat kontrol emosi, suasana hati (mood) dan memori, sehingga meningkatkan gelombang alfa dalam otak. Pengaturan ini membuat rileks dan dapat menurunkan aktifitas vasokonstriksi pembuluh darah, aliran darah menjadi lancar sehingga menurunkan tekanan darah (Sharma, 2008).

Pemberian aromaterapi minyak kenanga terbukti berpengaruh dalam menurunkan tekanan darah pada penderita hipertensi sehingga aromaterapi minyak kenanga dapat dijadikan sebagai salah satu intervensi keperawatan non-farmakologis dalam menurunkan tekanan darah pada penderita hipertensi (Shaleha, 2016). Hasil penelitian Majidi \& Juanita, (2013) yang berjudul pemberian aromaterapi kenanga untuk menurunkan tekanan darah lansia yang menyimpulkan terdapat perbedaan tekanan darah sebelum dan sesudah pemberian aromaterapi kenanga pada pasien hipertensi.

Berdasarkan hasil penelitian, peneliti bahwa dengan pemberian aromaterapi kenanga dapat meningkatkan gelombang alpha di otak yang menyebabkan menurunnya vasokontriksi pada pembuluh darah dan melancarkan sirkulasi darah, sehingga terjadinya penurunan tekanan darah. 


\section{KESIMPULAN DAN SARAN}

\section{Kesimpulan}

Ada pengaruh pemberian aromaterapi kenanga (cananga odorata) terhadap penurunan tekanan darah pada pasien hipertensi di Rumah Sakit Royal Prima Medan.

\section{Saran}

Hasil penelitian ini diharapkan dapat memberikan manfaat bagi penderita hipertensi dalam memberikan terapi pengobatan yang aman tanpa efek farmako dan mudah untuk digunakan setiap hari tanpa efek samping ketergantungan.

\section{DAFTAR PUSTAKA}

Ali, B., Al-Wabel, N. A., Shams, S., Ahamad, A., Khan, S. A., \& Anwar, F. (2015). Essential oils used in aromatherapy: A systemic review. Asian Pacific Journal of Tropical Biomedicine. https://doi.org/10.1016/ j.apjtb.2015.05.007

Gnatta, J. R., Piason, P. P., Lopes, C. de L. B. C., Rogenski, N. M. B., \& Silva, M. J. P. da. (2014). Aromatherapy with ylang ylang for anxiety and self-esteem: a pilot study. Revista Da Escola de Enfermagem Da USP. https://doi.org/10.1590/s0080623420140000300015

Kemenkes RI. (2019). Hipertensi si pembunuh senyap. Kementrian Kesehatan RI.

Kementerian Kesehatan RI. (2019). Laporan Nasional Riskesdas 2018. Badan Penelitian Dan Pengembangan Kesehatan. https://doi.org/978-602-373-118-3
Kumanan, T., Guruparan, M., \& Sreeharan, N. (2018). Hypertension "The Silent Killer": A guide for primary carephysicians and healthcare professionals. Colombo Chennai: Kumaran Book House.

Majidi, A. A., \& Juanita, F. (2013). Pemberian aromaterapi kenanga (cananga odorata) untuk menurunkan tekanan darah lansia di dusun Sumlaran Desa Sukodadi Kecamatan Sukodadi Kabupaten Lamongan. Surya, 3.

Ningsih, D. L. R., \& Indriani. (2017). Faktor-faktor yang berhubungan dengan kejadian hipertensi pada pekerja sektor informal di Pasar Beringharjo Kota Yogyakarta. Naskah Publikasi. https://doi.org/http://dx.doi.org/10.10 16/j.brainres.2009.04.039

Potter, P. A., \& Perry, A. G. (2015). Fundamental Keperawatan Buku 1 Ed. 7. In Jakarta: Salemba Medika. https://doi.org/IOS3107-49534

Shaleha, D. (2016). Pengaruh pemberian aromaterapi minyak kenanga terhadap penurunan tekanan darah pada penderita hipertensi di Desa Sebubus Kecamatan Paloh Kabupaten Sambas. Fakultas Kedokteran Universitas Tanjungpura Pontianak.

Sharma, S. (2008). The secret benefits of aroma therapy: Secret guides. New Delhi: Sterling Paperbacks.

World Health Organization. (2013). A global brief on Hypertension - World Health Day 2013. In World Health Organization. https://doi.org/10.1136/bmj.1.4815.8 82-a

World Health Organization. (2016). Global health observatory data: raised blood pressure.

Zulmi, A. . (2016). Pengaruh masase punggung terhadap kualitas tidur pada lansia di UPT PSLU Jember. Digital Repository Universitas Jember. 